\title{
CD56 (NCA M) Expression in Pancreatic Carcinoma and the Surrounding Pancreatic Tissue
}

\author{
YOSHIKI NAITO, HISAFUMI KINOSHITA*, YOSHINOBU OKABE**, \\ RYUICHI KAWAHARA*, TAKENORI SAKAI*, HIDEYA SUGA **, \\ SHUNJI ARIKAWA ${ }^{\dagger}, \mathrm{KOICHI} O S H I M A$ \\ AND MASAMICHI KOJIRO \\ Departments of Pathology, Surgery*, Medicine** and Radiology", \\ Kurume University School of Medicine, Kurume 830-0011, Japan
}

Received 12 September 2006, accepted 13 November 2006

\begin{abstract}
Summary: Expression of CD56, also known as the neural cell adhesion molecule (NCAM), in the pancre atic ducts of chronic pancreatitis is considered to represent a regenerative process of the pancreatic duct sys tem. CD56 expression was analyzed in 25 tissue samples of invasive ductal carcinoma without mixed ductalendocrine carcinoma of the pancreas, and in the surrounding non-cancerous pancreatic tissue. CD56 expres sion was detected in intercalated ducts (ICDs) of lobules in the pancreatic parenchyma showing chronic inflammation close to the carcinoma, but not in the carcinoma itself, in all cases. CD56 showed strong, diffuse expression in the areas with severe inflammation, but expression was weak in ICDs where the inflammation was mild. We suggested that CD56 expression is degenerative process in pancreatic tissue with chronic inflammation, and that examination of CD56 expression may be helpful in the differentiation of aty pical degenerative ducts from cancerous ducts.
\end{abstract}

Key words pancreas, pancreatitis, pancreatic carcinoma, CD56 (NCA M), intercal ated duct

\section{INTRODUCTION}

CD56, known as the neural cell adhesion molecule (NCAM), is a member of the immunoglobulin supergene family, and mediates homophilic binding between cells or between cells and matrix. In human pancreas, CD56 expression has been well documented in normal islet cells and endocrine tumors, and can be identified in fetal duct epithelium, the pancreatic bunds of the early rat embryo, and tumors such as solid-pseudopapillary tumors, acinar cell carcinomas, and pancreatoblastoma [1-5]. Recently, CD56 expression in the epithelial cells of the pancreatic ducts was reported in patients with chronic pancreatitis, and the expression was considered to be part of a regenerative process in the pancreatic duct system [5]. In the present study, we analyzed CD56 expression in pancreatic carcinoma and in noncancerous tissue with chronic inflammation in the vicinity of the carcinoma.

\section{MATERIALSAND METHODS}

We examined 25 resected cases of invasive ductal carcinoma of the pancreas, with chronic pancreatitis in the surrounding tissues, but without mixed ductal-endocrine carcinoma, at Kurume University Hospital. We studied two areas, (i) cancerous tissues and the surrounding non-cancerous tissues with chronic inflammation and (ii) pancreatic tissues far from the carcinoma. The resected specimens were fixed in $10 \%$ formalin, embedded in paraffin, and processed routinely. Immunohistochemical examina tion was carried out by the using streptavidin/Biotin

Correspondence to: Y oshiki Naito, MD., Department of Pathology, Kurume University School of Medicine, 67 A sahi-machi, Kurume $830-0011$, Japan. Tel: +81-942-31-7546 Fax: +81-942-32-0905 E-mail: nyoshiki@ med.kurume-u.ac.jp 
immunoperoxidase method. Briefly, after dehydra tion, slides were immersed in citrate buffer ( $\mathrm{PH}$ 6.0) and irradiated in a microwave oven for $10 \mathrm{~min}$. A fter cooling for $30 \mathrm{~min}$ at room temperature, sections were incubated for $1 \mathrm{hr}$ with anti-CD56 (Novocastra, Newcastle upon Tyne, U.K) monoclonal antibodies.

\section{RESULTS}

\section{Histological findings}

\section{Pancreatic carcinoma}

A Il tumors were well-differentiated adenocarcinoma with a tubular pattern and abundant fibrous stroma, and non-cancerous pancreatic tissue was intermingled at the boundary of the carcinoma (Figs. 1a, 1b).

\section{Non-cancerous pancreatic tissues}

The pancreatic tissues around the carcinoma showed severe inflammatory cell infiltration with lymphocytes and plasma cells and fibrosis, and atypical degenerative intercalated ducts (ICDs) were frequently observed (Fig. 2). However, the pancreatic tissues far from the carcinoma showed no inflamma tory change.

\section{Immunohistochemistry}

CD56 expression in pancreatic carcinoma

CD56 expression was negative for cancerous tis

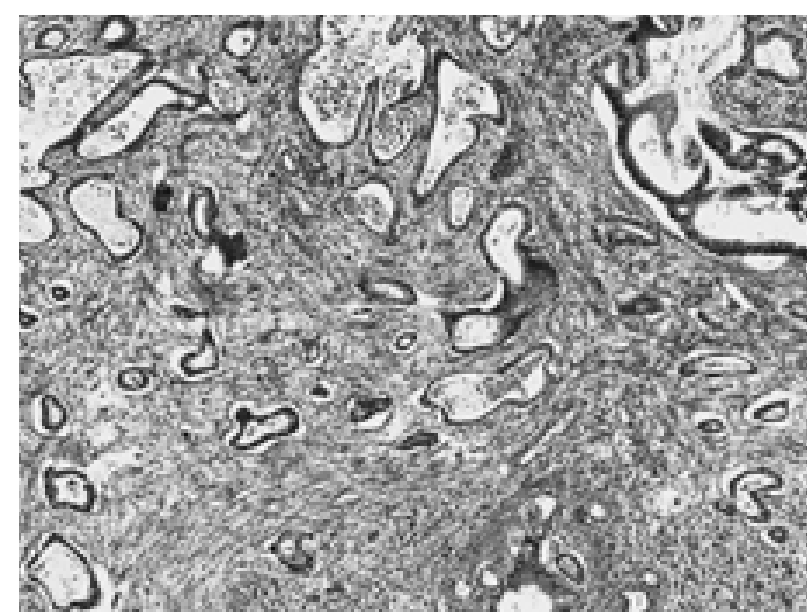

a

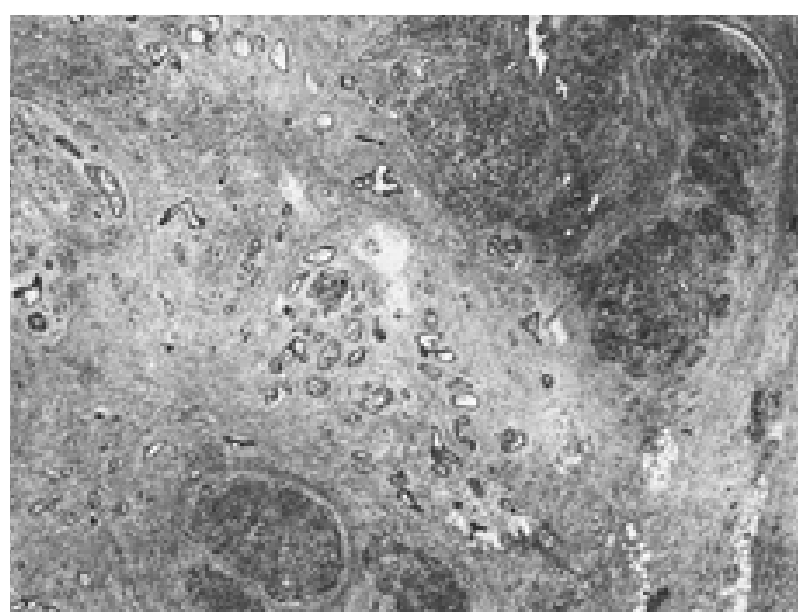

b

Fig. 1. (a): Invasive well-differentiated adenocarcinoma with stromal desmoplasia $(\times 40)$. (b): The boundary between ductal carcinoma and the surrounding non-cancerous pancreatic tissue with chronic inflammation $(\times 12.5)$.

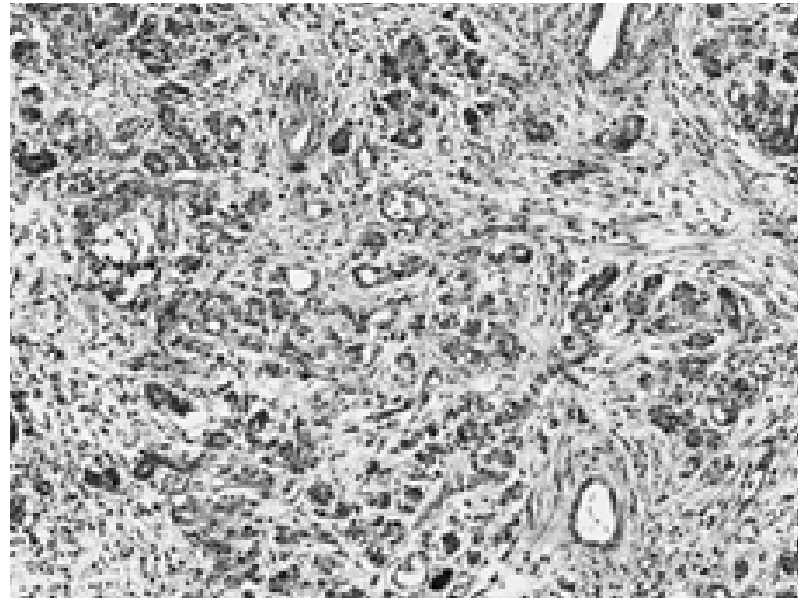

Fig. 2. The pancreatic tissues around the carcinoma showed severe inflammatory cell infiltration and atypical degenerative ICDs $(\times 100)$.

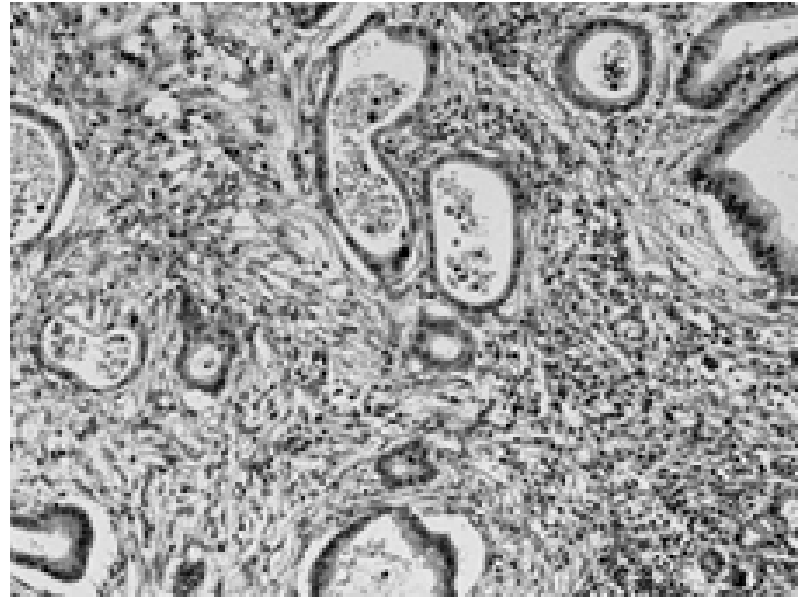

Fig. 3. CD56 was negative in the carcinoma ( $\times 100)$. 
sue in all cases (Fig. 3). In contrast, aty pical degenerative ICDs seen around the tumor boundaries expressed CD56 in varying degrees in all cases (Fig. 4). CD56 expression was diffuse and strong in the atypical degenerative ICDs of the areas with severe pancreatitis (Fig. 5a). However CD56 expression was only focally positive in normal ICDs of interlobules in pancreatic tissue far from the carcinoma with mild inflammation (Fig. 5b).

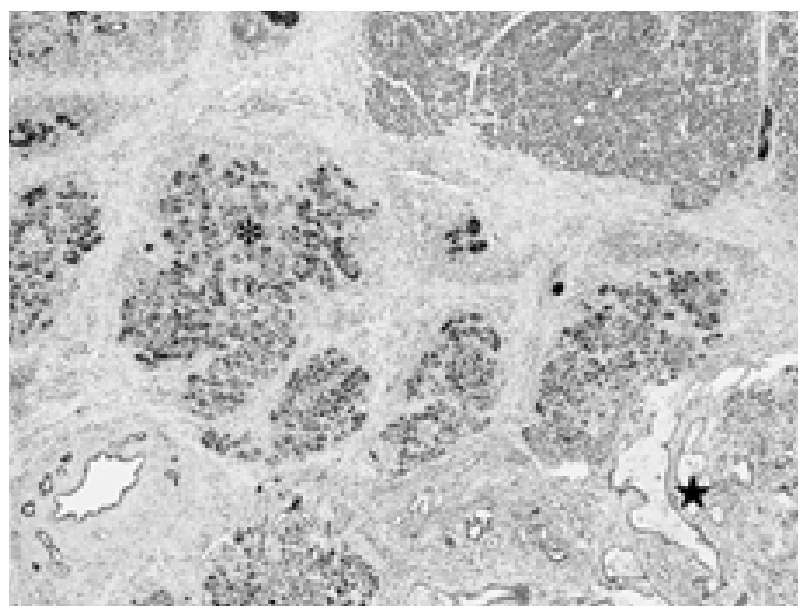

Fig. 4. CD56 was positive in the surrounding pancreatic tissues $(*)$ but negative in carcinoma $(\star)(\times 12.5)$.

\section{DISCUSSION}

CD56 expression in the pancreas has been reported in islet cells, scattered single ductal cells of fetuses, and ventral and dorsal pancreatic buds of the early rat embryo [1-5]. In addition, CD56 expression in epithelial cells was also reported in pancreatitis [5]. In the present study, CD56 expression was confirmed in ICDs in the pancreatic tissues in the vicinity of the carcinoma. On the other hand, CD56 expression was only focally positive in normal ICDs of interlobules in pancreatic tissue far from the carcinoma with mild inflammation.

Fujisawa et al. [5] reported 2 types of CD56 expression in ICDs of the pancreatic duct system. In the earlier stage of gestation, they were mostly endocrine cells and were related to islet neogenesis. In contrast, the CD56 expression in ICDs, which is common in the later stage of pregnancy, in infants, and in chronic pancreatitis, is probably unrelated to endocrine cells. In the present study, CD56 expres sion was detected in atypical ICDs of the pancreatic tissue showing chronic inflammation, and those CD56 positive cells may also represent a degenera tive process of the pancreatic duct system. In contrast, ICDs of the pancreatic tissue far from the carcinoma with no inflammation were negative for CD56. These findings may support the suggestion that degeneration is a possible cause of CD56 expression in ICDs.

CD56 expression was negative for cancerous tis sue in all cases. In the pancreatic tissues with chronic

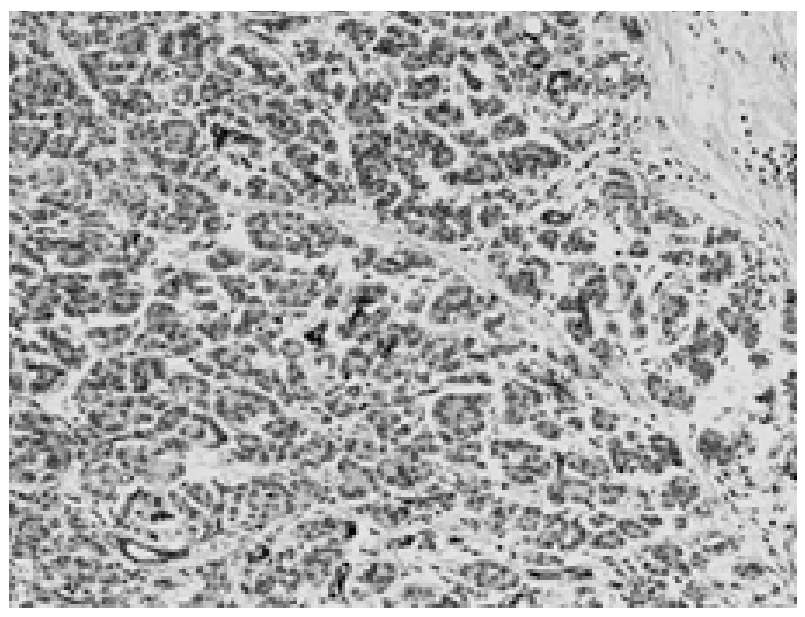

b

Fig. 5. (a): CD56 expression was diffuse and strong in the atypical degenerative ICDs of the severe pancreatitis ( $\times 100)$. (b): There was no CD 56 expression in ICD s of pancreatic tissues far from the carcinoma $(\times 100)$. 
inflammation, degenerative ICDs are increased and are frequently atypical, and it is sometimes difficult to distinguish those atypical ducts from well-differentiated ductal carcinoma with a tubular pattern [6]. In the present study, degenerative ICDs, including atypical ICDs in the areas with chronic inflamma tion, ex pressed CD56 diffusely and strongly, but cancerous tissues were negative for CD56 in all cases. The examination of CD56 expression is thought to be useful in differentiating degenerative ICDs from well-differentiated cancerous ducts.

\section{REFERENCES}

1. Gaidar YA, Lepekhin EA, Sheuchetova GA, and Witt M. Distribution of N-Cadherin and NCAM in neurons and endocrine cells of the human embryonic and fetal gas troenteropancreatic system. A ct Histochem 1998; 100:8397.

2. Lackie PM, Zuber C, and Roth J. Polysialic acid of the neural cell adhesion molecule (N-CAM) is widely expressed during organogenesis in mesodermal and endodermal derivatives. Differentiation 1994; 57:119-131.

3. Esni F, Taljedal IB, Perl AK, Cremer H, Christofori G et al. Neural cell adhesion molecule (N-CAM) is required for cell type segregation ad normal ultrastructure in pancreatic islets. J Cell Biol 1999; 144:325-337.

4. Notohara K, Hamazaki S, Tsukayama C, Nakamoto S, Kawabata K et al. Solid-pseudopapillary tumor of the pancreas: immunohistochemical localization of neuroendocrine markers and CD10. Am J Surg Pathol 2000; 24:1361-1371.

5. Fujisawa M, Notohara K, T sukayama C, Mizuno R, and Okada S. CD56-positive cells with or without synaptophysin expression are recognized in the pancreatic duct epithelium: a study with adult and fetal tissues and specimens from chronic pancreatitis. Acta Med Okayama 2003; 57:279-284.

6. Y amaguchi K, Chijiiwa K, Saiki S, Nakatsuka A, and Tanaka M. "Mass forming" pancreatitis masquerades as pancreatic carcinoma. Int J Pancreatol 1996; 20:27-35. 